\title{
Current Practice
}

\section{TO-DAY'S DRUGS}

\section{Progestational Agents}

\section{Secretion and Metabolism of Progesterone}

Progesterone is produced and secreted by the adrenal cortex, the ovary, and the placenta. Useful information about its distribution has been obtained by the use of radioactive isotopes. After the administration of radioactive progesterone to humans $40-70 \%$ of the dose may be recovered from the urine and $13-20 \%$ from the faeces. Most of this radioactivity is excreted within the first four days of administration of the labelled progesterone, although smaller amounts of radioactivity continue to be excreted for longer periods of time. Progesterone is taken up by the fat compartment of the body tissues and has been isolated from human fat obtained during the secretory phase of the cycle and during pregnancy. In one patient who was undergoing a therapeutic interruption of pregnancy ${ }^{1}$ about $10 \%$ of the administered radioactivity was found to be present in the fat tissues as long as six days after the injection of radioactive progesterone.

\section{Excretion Studies}

The main metabolites of progesterone are the reduced compounds, pregnanolone and pregnanediol, and until recently most of our knowledge concerning the amounts of progesterone secreted, both normally and under different physiological conditions, was obtained by measuring the urinary excretion of pregnanediol. On an average about one-sixth of the progesterone produced appears to be excreted in the urine as pregnanediol.

In women during the proliferative phase of the menstrual cycle, in post-menopausal females, and in males, up to $1-2 \mathrm{mg}$. per day of pregnanediol may be found in the urine; this appears to come predominantly from the adrenal cortex. During the luteal phase of the menstrual cycle the amounts of pregnanediol excreted rise to a peak between the 18th and 24 th days of the cycle and reach values of 3-7 $\mathrm{mg}$. per day. This rise in pregnanediol excretion reflects the secretion of progesterone by the developing corpus luteum. If conception does not occur pregnanediol excretion then begins to fall and menstruation ensues, reflecting the regression of the corpus luteum. If conception takes place the fall of pregnanediol excretion in the latter part of the luteal phase of the menstrual cycle is not seen, and pregnanediol excretion continues to rise slowly, reaching a value of about $15 \mathrm{mg}$. per day at the 20th week.

From the 20th to the 30th week of pregnancy pregnanediol excretion increases rapidly and by the 30th week it has reached a value of around $40 \mathrm{mg}$. per day ; thereafter it remains almost steady until parturition occurs. After parturition pregnanediol excretion rapidly falls to non-pregnant levels. By the use of radioactive progesterone it can be shown that during midpregnancy the daily progesterone production is about $75 \mathrm{mg}$. and that at the end of pregnancy this production reaches a value between 250 and $300 \mathrm{mg}$. These figures, together with those suggesting that the daily production of progesterone at the peak of the menstrual cycle is about $30 \mathrm{mg}$. per day, are very much higher than was thought until recently, and must be borne in mind when considering therapy with progestational agents.

\section{Blood Levels}

In spite of the large amounts of progesterone produced the amounts of progesterone detected in blood are low even during pregnancy. From the 20th to the 30th week the level seems to be about $5 \mu \mathrm{g}$. per $100 \mathrm{ml}$. of plasma ; thereafter there is a rapid rise over the course of the next six weeks to a value around $12 \mu \mathrm{g}$. per $100 \mathrm{ml}$. of plasma, and the level then appears to remain fairly steady until parturition occurs. These low blood levels are due to the rapid metabolism of progesterone, and by the use of the labelled hormone it can be shown that at the end of pregnancy the turnover time (that is, the time required for the total amount of circulating progesterone to be replaced) is of the order of three minutes. Within 15 minutes of giving labelled progesterone only small amounts of radioactivity are found in the plasma, and this radioactivity is associated mainly with the metabolites of progesterone and only to a small extent with progesterone itself. The rapid disappearance of progesterone from the plasma appears to be due to the rapid diffusion into the body fat and to rapid metabolism by the liver and excretion by the kidney.

\section{Synthetic Progestational Compounds}

Some of the problems of therapy with progesterone have been overcome by the production of synthetic steroids which are not only very much more active than progesterone but which, unlike progesterone, are active after oral administration. A selection of the most commonly used compounds is shown overleaf; these can be divided into three groups depending upon their chemical structure. All the compounds with the exception of $17 \alpha$-hydroxyprogesterone caproate are administered orally.

Group I contains those compounds related to progesterone, and modifications introduced include ether formation, as in the case of the cyclopentyl enol ether, or a change in the spatial configuration of the molecule at positions 9 and 10 with the production of a stereoisomer of progesterone known as retroprogesterone ; isopregnenone is 6-dehydroretroprogesterone. Progesterone cyclopentyl enol ether is the only one of the synthetic compounds which is metabolized to pregnanediol, and this synthetic compound may owe its activity to the slow release of progesterone in the body.

Group II contains those compounds derived from $17 \alpha$-hydroxyprogesterone, which is itself inactive, either by esterification of the $17 \alpha$-hydroxyl group or by esterification plus the introduction of other substituents. 17a-Hydroxyprogesterone caproate is a depot preparation administered intramuscularly, but its ready solubility in oil allows large amounts to be injected in a small volume of vehicle $(250 \mathrm{mg}$. in $1 \mathrm{ml}$.). This compound exerts a prolonged action lasting for seven to ten days, and one injection of $250 \mathrm{mg}$. is sufficient to bring about complete secretory transformation of the oestrogenprimed endometrium.

Group III contains those compounds related to testosterone or 19-nortestosterone. Norethynodrel, ethynodiol diacetate, gestanin, and lynestrenol also differ slightly from 19-nortestosterone in the structure in Ring A. Ethisterone, which is related to testosterone, was the first of the orally active progestogens to be synthesized and used, but it has now been superseded by the newer preparations. 
The compounds listed in Group III are slightly oestrogenic and are probably metabolized to oestrogenic compounds in the body. The effect of small changes in structure on the action shown by various synthetic compounds is well illustrated by two of the compounds in Group III. Gestanin has a progestational effect on the endometrium and strong pregnancy-maintaining properties; whereas lynestrenol, which has an ethinyl group $(-\mathrm{C} \equiv \mathrm{CH})$ instead of the allyl group $\left(-\mathrm{CH}_{2}-\mathrm{CH}=\mathrm{CH}_{2}\right)$ present in gestanin, will not maintain pregnancy in experimental animals.

Little is known so far regarding the metabolism of the progestational compounds. When labelled norethisterone and norethynodrel were administered orally to humans, most of the dose was absorbed ; about $70 \%$ of the dose was excreted in the urine and faeces, mainly within the first two days of administration. The prolonged action of $17 \alpha$-hydroxyprogesterone caproate appears to be due to slow absorption from the site of injection and possibly also to slow excretion.

\section{Assay of Progestational Compounds}

The main actions of progesterone are, in conjunction with oestrogens, to transform the uterine endometrium from the proliferative to the secretory stage in readiness for the implantation of the fertilized ovum and to maintain conditions for the delivery of a viable foetus at term. These two aspects of the action of progesterone are used in the assay of progestational agents. The Clauberg test makes use of ovariectomized mature rabbits or immature animals ; after appropriate priming with oestrogens the progestational agent is administered and the progestational changes taking place in the endometrium of the uterus are graded. Other animal tests used include the ability of the compound to maintain pregnancy or deciduomata in rats or mice which have been ovariectomized after fertilization and the ability to inhibit ovulation.

\begin{tabular}{|c|c|c|}
\hline & TRIVIAL NAME & CHEMICAL NAME \\
\hline 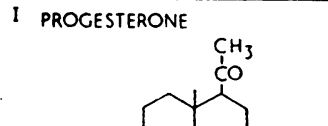 & $\begin{array}{l}\text { ENOL LUTEOVIS } \\
\text { ISOPRECNENONE }\end{array}$ & $\begin{array}{l}\text { PROCESTERONE CYCLOPENTYL- } \\
3 \text {-ENOL ETHER } \\
\text { 6- DEHYDRO- } 9 \beta, 10 \alpha-P R O- \\
\text { CESTERONE }\end{array}$ \\
\hline $\begin{array}{l}\text { ROXYPROGESTERONE } \\
\text { CH3 } \\
\text { CO } \\
4-\mathrm{H}_{3}\end{array}$ & $\begin{array}{l}\text { 17 } \alpha \text { - HYDROXYPROCEST- } \\
\text { ERONE CAPROATE } \\
\text { PROVERA } \\
\text { MECESTROL } \\
\text { CHLORMADINONE } \\
\text { CESTOVIS }\end{array}$ & 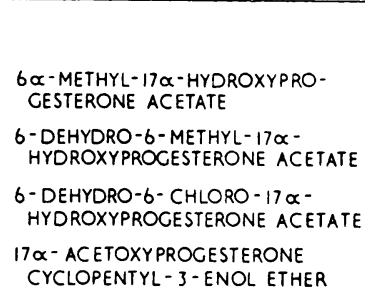 \\
\hline II TESTOSTERONE & $\begin{array}{l}\text { ETHISTERONE } \\
\text { DIMETHISTERONE }\end{array}$ & $\begin{array}{l}17 \propto-\text { ETHINYLTESTOSTERONE } \\
6 \propto, 21 \text { - DIMETHYLETHISTERONE }\end{array}$ \\
\hline 19-NORTESTOSTERONE & $\begin{array}{l}\text { NORETHISTERONE } \\
\text { NORETHISTERONE } \\
\text { ACETATE } \\
\text { LYNESTRENOL } \\
\text { CESTANIN } \\
\text { NORETHYNODREL } \\
\text { ETHYNODIOL } \\
\text { DIACETATE }\end{array}$ & 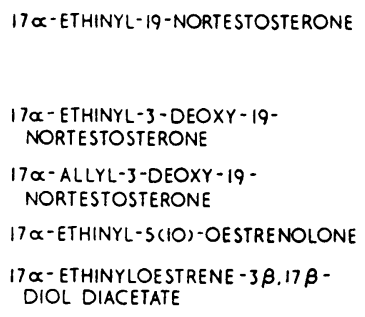 \\
\hline
\end{tabular}

Results of animal tests, however, do not always agree with the activity of the compounds in humans, so that the need for rigorously conducted clinical trials is obvious. In humans the activity can be assessed (1) by the examination of endometrial biopsy material from subjects receiving the progestational agents ; (2) by the ability of the compounds to inhibit ovulation as shown by the failure of pregnanediol excretion to rise during the second half of the cycle ; or (3) by the postponement of menstruation assay, in which the progestogen is administered from the 20th day of the cycle for 20 days, and the minimum dose required to postpone menstruation until the end of tablet taking is estimated.

Most of the compounds in Groups II and III appear to be highly active in this last test, although many of the compounds require oestrogen to be administered at the same time. The compounds in Group I had low activity and curiously enough so did provera. Compounds in Groups II and III are potent inhibitors of ovulation (although some may require oestrogen to be added) and when administered from the 5 th day to the 25 th day of the menstrual cycle will suppress the endogenous ovarian production of oestrogen and progesterone. Compounds in Group I have only a very weak activity in inhibiting ovulation.

\section{Therapeutic Use}

The following are generally recognized as the indications for the use of progestational compounds.

\section{Premenstrual Tension}

Progesterone administered during the second half of the cycle is usually effective in providing relief in this state. The availability of oral progestational compounds has made treatment much simpler, although these may not always be as effective as progesterone. Thus, in a trial in which ethisterone, dimethisterone (10-20 mg. daily), and norethisterone (10-15 mg. daily) were compared with progesterone (25-100 mg. daily), the synthetic compounds produced moderate to good relief in only about $60 \%$ of the patients tested, although all of the patients obtained good relief with progesterone. ${ }^{2}$ It was also noticed that patients who responded to one oral preparation did not necessarily respond to another.

\section{Dysmenorrhoea}

It has been known for a long time that dysmenorrhoea could be prevented by inhibiting ovulation, and some have considered the cause of this condition to be the endogenous production of progesterone. Stilboestrol has been used to inhibit ovulation in dysmenorrhoea, and more recently the progestational agents administered from day 5 to day 25 of the menstrual cycle have been used for the same purpose. In a recent study ${ }^{3}$ both norethisterone and isopregnenone in doses of $15 \mathrm{mg}$. daily were effective in reducing the pain of dysmenorrhoea in about $80 \%$ of the patients. It was of interest that isopregnenone at this dose level did not inhibit ovulation as shown by measuring changes in pregnanediol excretion and in the basal body temperature, and by observing at laparotomy a freshly formed corpus luteum in patients who had received the compound. When administered later in the cycle isopregnenone was not as effective as when started on day 5 . 


\section{Dysfunctional Uterine Haemorrhage}

This can be defined as bleeding from the non-pregnant uterus caused by a disturbance of endocrine control of menstruation rather than by local organic disease. The progestational agents can be used to treat this condition, and oral medication (5-15 mg. daily) gives a better control over the withdrawal bleedings than depot preparations. Some consider that the progestogens should be administered so as to suppress ovarian hormone production and to control breakdown of the endometrium by withdrawal bleedings; in these circumstances the capacity of the progestational compounds to control excessive haemorrhage is similar to their power to inhibit ovulation. Haemostasis occurs quickly on administration of the progestogen, but the cure is not permanent in most cases and patients tend to relapse when treatment is stopped.

Others consider there is insufficient progestational change in the endometrium, possibly owing to defective secretion of progesterone, and that therapy should be given from the 15 th to the 25th day of the cycle to supplement endogenous progesterone. Treatment with progestational agents should not be started until an organic cause of the bleeding has been eliminated.

\section{Amenorrhoea and Infertility}

In patients with amenorrhoea artificial cycles can be produced by the administration of a progestogen (10-15 mg. daily) from day 15 to day 25 of the cycle following the oestrogen priming of the endometrium during the preceding 10 days; termination of therapy is followed by withdrawal bleeding. It has been suggested that by continuation of this process for at least three cycles some patients with amenorrhoea will show an improvement in ovarian function due to intermittent inhibition of pituitary activity, a process which has been called the "rebound effect." A similar process has been suggested in cases of infertility where no discernible cause exists. However, the results obtained are not such that they would be convincing that the treatment is very effective. Administration of progestogens during the latter half of the cycle to produce a secretory endometrium has also been suggested in some cases of subfertility if corpus luteum insufficiency is suspected.

\section{Endometriosis}

Continuous treatment with one of the ovulation-suppressing steroids is used to suppress ovarian function and to prevent periodic shedding of the endometrium. Combined progestogenoestrogen therapy is indicated and one or two tablets per day of any of the preparations used as oral contraceptives would be suitable.

\section{Threatened and Habitual Abortion}

Pregnanediol excretion tends to be low in patients who abort although whether an insufficiency of progesterone is the cause or the result of the abortion is not yet clear. In many of the earlier attempts to prevent abortion by treatment with progesterone insufficient amounts of the latter were used. Some have advocated that treatment with progestational compounds should be used only in those cases which show a low or falling pregnanediol excretion. Since few of the investigations concerning the effect of progestogen treatment in abortion have been adequately controlled it is difficult to evaluate the effectiveness of the treatment. In a recent preliminary doubleblind study ${ }^{4}$ using patients with a low or falling pregnanediol excretion the salvage rate in the group receiving a placebo was not significantly different from that of the group receiving 17-hydroxyprogesterone caproate.

In treating pregnant patients with progestational agents the possibility of producing genital anomalies in the foetus should be considered. Only a small proportion of babies of treated mothers are affected, and Wilkins ${ }^{5}$ considers that the danger is not great enough to prohibit the use of these compounds in pregnancy. Similar anomalies may also arise spontaneously or after the use of progesterone. The main anomaly reported is that of female pseudohermaphroditism with masculinization of the external genitalia. The defect is usually not serious and readily corrected. The least androgenic compounds-for example, those in Group I or 17-hydroxyprogesterone caproate -should be used during pregnancy; suitable doses would be $10-40 \mathrm{mg}$. daily of the former and $125-250 \mathrm{mg}$. weekly of the latter, depending on the stage of the pregnancy.

\section{Oral Contraception}

Most of the compounds listed on the facing page are available in combination with synthetic oestrogens for use as oral contraceptives. This topic has previously been presented in “To-day's Drugs" (24 August, p. 489).

The compounds are also used in an oral pregnancy test and for the postponement of menstruation.

\section{REFERENCES}

1 Plotz, E. J., and Davis, M. E., Proc. Soc. exp. Biol. (N.Y.), 1957, 95, 92.

2 Dalton, K., Brit. med. f., 1959, 2, 1307.

s Bikhop, P. M. F., Proc. roy. Soc. Med., 1962, 55, 867.

4 Shearman, R. P., and Garrett, W. J., Brit. med. Y., 1963, 2, 292.

5 Jones, H. W., and Wilkins, L., Fertil. and Steril., 1960, 11, 148.

\section{Any Questions?}

We publish below a selection of questions and answers of general interest.

\section{Metabolic Basis for Intellectual Capacity}

Q.-Some cases of mental retardation are related to chemical abnormalities. Is it conceivahle that an above-average level of mental capability is also somehow dependent upon metabolic characteristics? If so, what might they be? Is any work being done to elucidate this important question?

A.-On theoretical grounds it would not seem unreasonable to suppose that intellec- tual capacity above the average level may depend upon inborn metabolic characteristics. It is natural that attention should have been focused initially upon the mentally subnormal, among whom biochemical errors were in the first place fortuitously discovered, but so far as is known a search has not yet been made for metabolic characteristics among the intellectually superior.

It would seem rational to approach the problem from a pharmacological angle. It is well known that drugs of certain classes influence psychological function, such as perception, in psychiatrically normal subjects who are not mentally retarded. Furthermore, certain psychiatric disorders, such as depression, which may temporarily hamper intellectual functioning in patients of average or superior intelligence, may be amenable to pharmacological treatment. No drug or chemical regime is known at the present time, however, to increase basic inborn intellectual potential in the absence of a pathological process or a recognized biochemical error which can be corrected. It is perhaps unrealistic to hope for such a discovery. Short of this, however, one may hope that with the rapid current development of pharmacabogical methods in psychiatry some light may be thrown upon such questions as whether there are 